\title{
Optimization the Parameters of Hotwire Cutting Process to Enhance the Properties of Polystyrene Foam
}

\author{
Israa Qassim Mohammed \\ Department of Automated Manufacturing Engineering, Al-Khwarizmi Engineering College, University of \\ Baghdad \\ Al-Jadriya campus, Baghdad, 10071, Iraq \\ Ali Husain Kadhum \\ Department of Automated Manufacturing Engineering, Al-Khwarizmi Engineering College, University of \\ Baghdad \\ Al-Jadriya campus, Baghdad, 10071, Iraq
}

\begin{abstract}
Hot -Wire cutting process is one of the important method to produce different shapes and prototypes of Extruded Polystyrene (XPS) and Expanded Polystyrene (EPS) material. The study and analysis of Hot-Wire cutting parameters play an important role to enhance the quality and accuracy of the process and products . The effect on the surface has been investigated by using the experimental test which designed according to the Taguchi orthogonal array (OA). In this study, four parameters, (temperature of wire $(\mathrm{A})\left({ }^{\circ} \mathrm{C}\right)$, diameter of wire $(\mathrm{B})(\mathrm{mm})$, velocity of cutting (C) $(\mathrm{mm} / \mathrm{min})$, and density of foam (D) $(\mathrm{gm} / \mathrm{cm} 3)$, with five levels for each parameter have been used. A full process would require $(45=625)$ experiments .The design of experiments(DOE)n performed L25(45) orthogonal array, which suggested by Taguchi to reduce the high required number of experiments to 25 effected tests. In the present study, the signal to noise $(\mathrm{s} / \mathrm{n})$ ratio have been performed for analysis the results, by statistical software(MINITAB17) to establish the optimum condition for a process and estimate the contributions and response under optimum condition. In addition, the analysis of variance (ANOVA) has been performed to identify the significant parameters affected on accuracy and quality.
\end{abstract}

Keywords: hotwire cutting, Polystyrene, foam cutting, Taguchi, ANOVA.

DOI: $10.7176 /$ ISDE/10-5-01

Publication date: June $30^{\text {th }} 2019$

\section{Introduction}

Hot-wire cutting process is one of the cutting methods which depends on the thermal process. It is used to cut different shapes and materials for variety of industries with high accuracy. Hot-wire cutting technique can be successfully used to cut such as plastic foams and similar material into desired shapes. today the products of plastic are an important and integral part of everything in ourlife. The process of manufacturing the plastic foam are the casting and extruding, so the perfect way to cut these types of foam is hotwire cutting.

Hot-wire cutting is thermo mechanical way to cut foam. in low volume manufacturing. This cutting can be performed with a source of heat (here is wire ) which change the physical properties of material until it can be cut with low cutting force.

There are several mechanisms for the thermomechanical cutting of plastic foam, these mechanisms make the cutting in the process and they can be divided into three-basic modes or the mixing among them. They are :

- Thermal cutting : in this mode the plastic foam is vaporized or just melting infront of the wire cutter but without touching between them. see Figure 1.a.

- Thermo-mechanical cutting : this mode is a mixing between the shearing force and the melting of material to perfume the cutting and the hot-tool in contact with the material. see Figure 1.b.

- Mechanical cutting : this mode depends on the shearing because it happen when the temperature of tool is bellow the melting point of the foam[3]. as shown in Figure 1.c

Simply the principle work is an electrical power pass through conductive wire (usually Nichrome wire) then the wire is heated to desired temperature degree according to the input voltage. The wire bow is heated through electrical resistance about $200 \mathrm{oC}$ by passing the current through the wire. When the wire contact the surface of foam, it melts the area surrounding it, the heat of the wire vaporises the foam, creating a smooth surface . Figure 2. shows the wire is moving across the specimen of foam material and the orders are given by the computer CNC machine to make the desired shape, so any 2D profile can be performed as in Figure 1.3.

The material to be cut is just soften under the point of melting because it is thermoplastic material, after that the cutting is done. The surface of the cut and kerf-width is affected by the changing of the feed rate even if it was small and the diameter of wire [3] .

Many researchers have studied the cutting process of polymers and the effective parameters on it . Ranjeet et al [4] make investigation in ablation process for the Expanded Polystyrene (EPS) rapid prototyping to predict and 
calculate the kerfwidth and surface roughness (Ra) with mathematical model. Kiril P. et al [5] propose a novel thermo-electro-mechanical model for hotwire cutting of EPS foam and predicts the stress, voltage and temperature of wire during cutting of EPS foam. Also find relation between kerfwidth and the cutting angle as measured from the horizontal direction. Namrata et al [6] investigates the factors responsible for the bowing phenomenon via a series of experiments involving variations in current and wire feed rate, build more precise prototypes, kerf width is also examined, Further more finding noval way to predict the influence of gases in bowing has been analyzed and quantified. M.Tech RIET [7] study the effect of parameters for the polymer cutting process on material removal rate and kerfwidth ,also the optimization of the machining process. Luka Ivanovskis [8] develop a 4-axis numerically controlled hot-wire foam cutter suitable for flying aircraft modelling purposes. Numerically controlled foam cutter had to be able to cut intricate shapes out of foam material such as extruded polystyrene by using 3D virtual model, also find novel mathematical model to predict the kerfwidth, and empirical relationship is established to predict the surface roughness $\left(R_{\mathrm{a}}\right)$ of the sliced surface by performing regression analysis.

The objective of this paper is to obtain the optimum cutting conditions for hotwire cutting process, and study the effect of these parameters on the MR, Kerfwidth and Dragline.

\section{MATERIAL AND METHOD}

\subsection{Foam used in hotwire cutting}

Extruded Polystyrene (XPS) foam is used in this study with different densities. Foam is a combination of polymer solid phase and gas mixed together too fast until it become as smooth as desired. The applications are virtually endless, ranging from items as small as a kitchen sponge to a soundproofing systems in cinemas [9].

\subsection{Implimentaation and assemply of parts of the Machine}

The machine consists of these parts as follow:

2.2.1. Hot-wire cutter CNC: The machine is very easily adjustable and therefore it is expected to provide a possibility for high accuracy, with specifications as shown in table 1 . The parts of hotwire CNC machine are controlled by the Universal G code sender software. The two stepper motors as shown in figure 3 of CNC machine are controlled through the UNO ARDUINO, this motors make together the movements of the two axes $\mathrm{X}$ and $\mathrm{Y}$ which are vertically and horizontally standing.

The cutter consists of an elbow of aluminum insulated by small ceramic cylinders on both ends as shown in figure 4 to avoid short circuit, and the wire of cut which is Nichrome (Nickel-Chromium alloy) .

The wire fixed on the ends of the arc as electrical connection to allow the current to pass through, so the wire will be heated to the desired degree according to the voltage that given from the DC regulated power supply as shown in figure 5. After that the cut can be start by giving orders from the computer to move motors.

2.2.2. UNO-ARDUINO Controller: The Adriano is platform which is an electronics of open source based on easy-to- use software and hardware. Arduino boards can read input ssensors), and transfer them to an output like : activatinga motor, or turningon a light emitting diode(LED). Arduino programming language (basedon wiring), and the Arduino Software integrated development environment (IDE), based on Processing. The UNO arduino type used for this project. It was engaged with the CNC shield. The voltage input to the shield is 12 volts supplies from the DC Switched-mode power supply (smps) as shown in Figure6, the parts are shown in the figure7. Table. 2 shows the relation between temperature and voltage.

The Arduino is connected to a computer via USB, which provide the information of motion commands to transfer through it. The Universal G-code Sender (which is platform of G-code with full featured used to interfacc between advanced controllers of CNC like GRBL used to send the G-code which is pre-made to the motors)[10]. The velocity of motors can be corrected by the Universal G-code Sender software from the settings. The figure8 illustrate the screenshot of the Gcode universal .

\subsection{Hot-Wire Process Parameters:}

2.3.1.Temperature of Wire(tests of temperature: The first parameter of cutting process is temperature of wire at the beginning the manual heat regular is replaced by variable voltage power supply to get the desired temperatures. The choose of suitable temperature to cut foam in this work come from the primary experiments (that not entered in tagauchi array) and relatively to the literature work of other researchers. So the temperature vary with the variety of voltages input from the power supply which can be tuned manually as in table 3.2. The desired temperatures are $(100,120,130,150,160)$. The wire receive voltage from the variable voltage power supply according to the diameter so the biggest one need less than voltage from the others to reach the desired temperature and so on .The temperature can be measured by the infrared thermo camera FLIR T335 as shown in figure 9.

2.3.2. Cutting Velocity of the Process(tests of cutting velocity): The second parameter was the velocity of motors which was chosen according to primary experiments that is the velocity of cutting. The velocity is controlled by the computer through the ARDUINO, the software which can translate the orders from the computer to the arduino then to make the movement of motors with the desired velocity was Universal G-code Sender, from the options 
before the start of cutting.

The decided velocities are: $(200,300,400,500,600) \mathrm{mm} / \mathrm{min}$.

Digital tachometer device can measure and determine the magnitude of velocities for the motors as shown in figure 3.

2.3.3. The Diameter of Wire : The third parameter which can effect very clearly on the performance of cut as kerf width , MR and dragline, is the diameter of cutting wire. that was chosen according to the available diameters in the market, and they are : $(0.3,0.4,0.5,0.7,0.8) \mathrm{mm}$. as shown in figure

2.3.4. The type of Polystyrene Foams (Density of foam):The fourth parameter of cutting process is the density of foam. The material of workpiece is generally XPS foam. the foam has different colors which they are :purple , yellow, blue, pink and white as shown in figure 3.11. these colors used to recognize each one according to the density . styrofoam XPS foam used in this study with different densities and colors .

\subsection{The Selection of the levels of the input Parameters}

Taguchi technique is an useful technique used in analysis and modeling. In this work, four important variables have effects on the cutting process. The process parameters were four factors with five levels for each one, that have a large impact on properties of foam, ( temperature of wire(A), diameter of wire (B), velocity of motors (C), and density of foam (D)). The factors and their levels are shown in table (3.4). Twenty five tests designed according to Taguchi matrix through the orthogonal array (OA). The analysis of the variance (ANOVA) technique was utilized to analysis the results, by using the statistical software (MINITAB-17), also to determine the most influence parameters affecting on the properties of foam. Taguchi technique was performed to establish the optimum parameter. The selection of the process parameters and their levels is listed in table (3.4) :

\subsection{Selection of the Orthogonal Array}

The orthogonal array (OA) is a technique used to reduce the number of the experiments, and can be obtained From the MINITAB17 software, in order the select of the appropriate OA for the experiments, each variable with five levels has two degree of the freedom DOF. In Taguchi method the DOF of selecting orthogonal array must be equal or larger than the total DOF required to the experiments, therefore; an OA L25 $\left(5^{\wedge} 4\right)$ of the four factors for the five levels are used in this work to find the most effective experiments (25 experiments) from the total experiment (625 experiments)

This orthogonal array has 25 rows and 4 columns, each columns represents specific process parameters while each row represents a trial condition [11].

The selected OA is listed in the table (3. 5), and the detailed experiment for hotwire cutting process array is represented in the table (3.4), so twenty five experiments were selected according to the OA by Taguchi technique. Table 4. OA of Taguchi

\subsection{Optimization the process parameters of hot-wire cutting}

The Taguchi Method is a statistical technique used to find the optimum values for the parameters in the experiments and reduce the number of experiments that have to be done [12,13 ]. Optimization of process parameters is done to make a great control to the quality, cost aspects and productivity of the process. It is effective way to improve quality of product at a relatively low cost. The Taguchi technique is very good tool to design systems of high quality

\subsection{Procedure of foam cutting operation}

The foam cutting process can be outlined as the steps in figure 11, which describe the whole process done by the machine and then the results can be processed with the MINITAB software.

\section{RESULT AND DISCUSSION}

\subsection{Signal to Noise Ratio $(S / N)$}

The $(\mathrm{S} / \mathrm{N})$ ratio is defined as standard approach where the result used for the average of the result is run with the main parameter. The optimum with $\mathrm{S} / \mathrm{N}$ ratio is studying, the main effect of the parameters and giving the optimum result which effect on the process. In the hotwire cutting process, the $\mathrm{S} / \mathrm{N}$ ratio is used to measure the sensitivity of the quality surface characteristic (kerf width, MR and Dragline) with the parameters. There are three categories of the quality characteristics: smaller is better, normal is better and larger is better, the aim of any experiment is always to determine the highest possible $(\mathrm{s} / \mathrm{n})$ for the result. in this study selecting the smaller is better which means the maximum response of the kerfwidth, (MR) and dragline with the smallest lost of material .

The mean squared deviation $(\mathrm{MSD}),(\mathrm{S} / \mathrm{N})$ ratio and prediction are determined by the equations (smaller is better) below:

$\operatorname{MSD}=\left(\frac{1}{n} \sum_{i=1}^{n}\left(\mathrm{y}^{2}\right)\right)$ 
$(\mathrm{s} / \mathrm{n})$ ratio $=-10 \log _{10}\left(\frac{1}{n} \sum_{i=1}^{n}\left(\mathrm{y}^{2}\right)\right)$

Where:

$\mathrm{n}:$ is the number of the trial

$\mathrm{i}$ : is trial number

The following results will be analyzed by using (MINIITAB17).

3.1.1. Analysis of the Material Removal with the Hot-Wire Cutting Parameters

The analysis of material removal is explained with the parameters by using $(\mathrm{S} / \mathrm{N})$ ratio, describes the quality of the surface in the hotwire cutting process. The results have been analyzed by using $\mathrm{S} / \mathrm{N}$ ratio to obtain the optimal level for each process parameter that has larger effect of the surface quality. The main effect of each parameter with four level on the $\mathrm{S} / \mathrm{N}$ ratio and mean for material removal are calculated in the tables $(6,7)$, the plot of the $\mathrm{S} / \mathrm{N}$ ratio and mean is shown in the figure $(12,13)$. Note: there are 4 experiments failed through cutting, so they neglected in all calculations .

From the tables $(6,7)$, the effect of each factor (Rank) can be seen which mean the effect degree of each factor on the MR. In addition, the optimal level of the parameters with MR is calculated according to the larger value of the mean and $\mathrm{S} / \mathrm{N}$ ratio, so in this case the rank of optimal parameters which effected on the MR is: wire temperature (A), followed by density (D), then the wire diameter(B) and velocity of cut (C), and It noticed that the optimal condition is : A1 , B3, C2, D4 for s/n ratio, and A2, B4, C1, D3 for means .

Figures $(12,13)$ show the plots of SN ratio and Mean of the MR for the material.

For this situation, we need to make a prediction. This can be used to predict the optimum level of $\mathrm{S} / \mathrm{N}$ ratio and mean, then choosing the optimum level which depends on the large value of the $\mathrm{S} / \mathrm{N}$ ratio [ 14] as shown in table 8

From the table 8 the optimum predict value for $\mathrm{s} / \mathrm{n}$ ration is 63.3489 which is the larger, that mean in the conditions of :A1(100 C), B3(0.5mm), C2(300mm/min), $\mathbf{D 4}\left(0.032 \mathrm{gm} / \mathrm{cm}^{3)}\right.$ the material removal is in the smallest removed amount which is the optimum result.

3.1.2. Analysis of the KerfWidth with Hot-Wire Cutting Parameters:

In this part, the analysis of the kerfwidth is explained with the factor to describe the quality of the surface in the hotwire cutting process. The results have been analyzed by using $\mathrm{S} / \mathrm{N}$ ratio to obtain the optimal level for each process parameter which that larger effect of the quality surface. The main effect of each parameters with five levels on the $\mathrm{S} / \mathrm{N}$ ratio and mean for kerf width are calculated in table $(9,10)$, the plot of the $\mathrm{S} / \mathrm{N}$ ratio and mean is shown in the figure $(14,15)$.

From the tables $(9,10)$ the effect of the each factor (Rank) can be seen which mean the effect degree of each factor on the kerfwidth, in this case, although the same Rank for the results of the $\mathrm{S} / \mathrm{N}$ ratio and the mean but the optimal level for both is the difference as shown in the tables (9.10). The optimum level of the $\mathrm{S} / \mathrm{N}$ ratio is $\mathbf{A 2}, \mathbf{B 2}$, C3, and D4 shown with yellow color and the optimum level of the mean results is A4, B5, C3, and D1 shown in the green color. For this situation, we need to make a prediction. This can be used to predict the optimum level of $\mathrm{S} / \mathrm{N}$ ratio and mean, then choosing the optimum level which depends on the large value of the $\mathrm{S} / \mathrm{N}$ ratio as shown in table 11.

Figures (4.2.a,b) show the plots of SN ratio and Mean of the kerfwidth for the material.

From the table 11 the optimum predict value for $\mathrm{s} / \mathrm{n}$ ration is 32.7496 which is the larger, that mean in the conditions of :A2(120 C), B2(0.4mm), C3(400 mm/ $\mathbf{m i n}), \mathbf{D 4}\left(0.032 \mathrm{gm} / \mathbf{c m}^{3)}\right.$ the kerfwidth is in the smallest value which is the optimum result.

3.1.3. Analysis of the Dragline with the Hot-Wire Cutting Parameters

The analysis of material removal is explained with the parameters by using $(\mathrm{S} / \mathrm{N})$ ratio, describes the quality of the surface in the hotwire cutting process. The results have been analyzed by using $\mathrm{S} / \mathrm{N}$ ratio to obtain the optimal level for each process parameter that has larger effect of the quality surface. The main effect of each parameter with four level on the mean and $\mathrm{S} / \mathrm{N}$ ratio for material removal are calculated in the table 12 , the plot of the mean and $\mathrm{S} / \mathrm{N}$ ratio is shown in the figure 13 .

From the tables (12,13), the effect of each factor (Rank) can be seen which mean the effect degree of each factor on the result. In addition, the optimal level of the parameters with Dragline is calculated according to the large value of the $\mathrm{S} / \mathrm{N}$ ratio and mean, so in this case the optimal parameters which effected on the DRAGLINE is density (D), followed by velocity of cut (C) then the wire diameter (B), and wire temperature (A). It noticed that the optimal condition is : A2,B4,C1,D1 for s/n ratio ; and A2,B4,C4,D1 for means

So the prediction here is needed to reach the optimum of the result.

For this situation, we need to make a prediction. This can be used to predict the optimum level of $\mathrm{S} / \mathrm{N}$ ratio and mean, then choosing the optimum level which depends on the large value of the $\mathrm{S} / \mathrm{N}$ ratio as shown in table (14).

From the table 14 the optimum predict value for $\mathrm{s} / \mathrm{n}$ ration is 44.2893 which is the larger, that mean in the 
conditions of :A2(120 C), B4(0.7 mm), C1(200mm/min), D1 $\left(0.01 \mathbf{g m} / \mathbf{c m}^{3)}\right.$ the dragline is in the smallest amount which is the optimum result

\subsection{Analysis of the Variance (ANOVA)}

The optimum of the work accomplished by determine the percentage of each parameter on the results of the experiments. The ANOVA is a statistical treatment analysis which is used for this purpose for the MR , kerf width and draglines of surfaces[15].

3.2.1. ANOVA for the material removal of the foam

In this part, ANOVA is used to determine the influence of the parameters on the material removal as shown in the table 15 .

From this table, it is noticed that the significant effect of the parameter is the diameter (B 46.8\%) then the density (D 38.6\%) followed by the velocity(C 5.5\%), and temperature (A 3.4\%) as shown in figure 18 .

3.2.2. ANOVA for the Kerf Width of the foam

In this part, the ANOVA is used to determine the effect of the factors on the KERF WIDTH as shown in the table 16.

the figure20, it is noticed that the significant effect of the parameter is firstly the density (D 57.6\%) then the heat (A 15\%) followed by velocity (C 11.6\%) and diameter (B 4\%) .

From the figure20, it is noticed that the significant effect of the parameter is firstly the density (D 57.6\%) then the heat (A 15\%) followed by velocity (C 11.6\%) and diameter (B 4\%)

3.2.3.ANOVA for the dragline of the foam

In this part, the ANOVA is used to determine the effect of the factors on the KERF WIDTH as shown in the table 17.

\subsection{Regression equations for KerfWidth, MR and Dragline}

Regression is a statistical measure used to find and calculate the mathematical relationship between the independent variables and the dependant variables [16] or in other word the input and output parameters (as in this thesis) which is linear .

The general form of multiple regression is:

$\mathrm{y}=\mathrm{a}+\mathrm{b} 1 \times 1+\mathrm{b} 2 \times 2+\mathrm{b} 3 \times 3+\ldots+\mathrm{bt} \times \mathrm{t}+\mathrm{u} \ldots$

While :

$y:$ the output or the predicted variable

$\mathrm{x}$ : the input or the variable which is needed to find $\mathrm{y}$ value

a : constant

b : slope

$\mathrm{u}$ : the residual of regression

By using MINITAB software the regression equation for estimating the MR, kerfwidth and Dragline used to find the comparison between the experimentally and numerically results of them ,that has been obtained as the following:

\section{* Regression Equations:}

$\mathrm{Y} 1=-0.00551+0.000002 \mathrm{~A}+0.01008 \mathrm{~B}+0.000000 \mathrm{C}+0.2759 \mathrm{D}$

$\mathrm{Y} 2=-0.0034+0.001827 \mathrm{~A}+0.1510 \mathrm{~B}-0.000199 \mathrm{C}-4.08 \mathrm{D}$

$\mathrm{Y} 3=66.1+1.04 \mathrm{~A}-1.64 \mathrm{~B}-3.44 \mathrm{C}-6.95 \mathrm{D}$

Where :

A : the wire temperature

$\mathrm{B}:$ the wire diameter

$\mathrm{C}$ : the velocity of cutting

$\mathrm{D}:$ the density of foam

Y1: Material Removal

Y2: Kerfwidth

Y3: Dragline

\section{Conclusion}

The conclusions of this research are summarized as:

1. The optimization of the hot wire process found by Taguchi techniques, the optimal values of parameters for the highest cutting quality and accuracy have been found.

2.Develop the regression models to predict and analyses cutting quality and dimensional accuracy of hotwire process by using statistical software MINITAB17

3. The relationship between input and output parameters to improve the efficiency of the hot-wire foam process shows the optimization results : 
- The optimum values of MR are : the temperature is $100{ }^{\circ} \mathrm{C}$, diameter of wire is $0.5 \mathrm{~mm}$, velocity of cut is $300 \mathrm{~mm} / \mathrm{min}$ and density of foam is $0.032 \mathrm{gm} / \mathrm{cm}^{3}$. (the conditions A1,B3,C2 and D4)

- The optimum values of kerfwidth are : the temperature is 120 , diameter of wire is $0.4 \mathrm{~mm}$, velocity of cut is $400 \mathrm{~mm} / \mathrm{min}$ and density of foam is $0.032 \mathrm{gm} / \mathrm{cm}^{3}$ (the conditions A2,B2,C3 and D4)

- The optimum values of Dragline are: the temperature is $120^{\circ} \mathrm{C}$, diameter of wire is $0.7 \mathrm{~mm}$, velocity of cut is $200 \mathrm{~mm} / \mathrm{min}$ and density of foam is $0.01 \mathrm{gm} / \mathrm{cm}^{3}$ (the conditions A2,B4,C1 and D1).

4. The analysis of the variance for hotwire cutting process, found that:

- the Diameter of wire B has larger percent of effect on the $\mathrm{MR}(46.8 \%)$, followed by the density of foam D $(38.6 \%)$, then the velocity of cutting $\mathrm{C}(5.8 \%)$, and finally the temperature of wire A $(3.4 \%)$.

- also the Diameter of wire B has larger effect on the kerfwidth $(35 \%)$, followed by the temperature of wire A $(24.6 \%)$, then the density of foam $\mathrm{D}(20.3 \%)$, and finally the velocity of cutting $\mathrm{C}(10.6 \%)$.

- while the Density of foam D has the larger effect on dragline $(57.6 \%)$, followed by the temperature of wire $\mathrm{A}(15 \%)$, then the velocity of cutting $\mathrm{C}(11.6 \%)$. and finally the diameter of wire $\mathrm{B}(4 \%)$.

\section{References}

[1] H. Brooks , "Plastic Foam Cutting Mechanics for Rapid Prototyping and Manufacturing Purposes" (Ph.DThesis), Mechanical Engineeringat the University of Canterbury, Christ church, NewZealand, 2009.

[2] https://www.merryweather.com/capabilities/hot-wire-form-cutting

[3] Aitchison, D., Brooks, H., Bain., J., Pons, D.. “An Investigation into the Prediction of optimal Machining Conditions for Polystyrene Foam Cut with a Taut Hot-Wire". The Annals of "Dunarea de Jos" University of Galati, Fascicle V, Technologies in Machine Building, ISSN 1221- 4566. 2009

[4] Ranjeet K. B. , Sajan K. ,Pushkar K. \&K. P. Karunakaran , “Investigation of ablation studies of EPS pattern produced by rapid prototyping", 2018

[5] Kiril P.Petkov, Jesper H.Hattel" A thermo-electro-mechanical simulation model for hot wire cutting of EPS foam" International Journal of Machine Tools and ManufactureVolume 107, Pages 50-59,2016.

[6] NamrataKarmakar , SathyanSubbiah, "Investigating Bowing of Hot Wire during cutting of EPS" Procedia Manufacturing Volume 26, Pages 671-680, 2018

[7] M.Tech student, RIET, Asst. Prof., MED, CTPC, Shahpur,'Influence on Kerf Width in Machining Polystyrene by Heating Element Profile Maker using Nichrome Wire"

[8] Harmanpreet Manpreet Singh Phagwara, India Jalandhar, India Vol. 4 Issue 04, April-2015 Luka Ivanovskis, “Four Axis Hot-Wire Foam Cutter Controlled by Mindstorms EV3 “ „Saimaa University of Applied Sciences Faculty of Technology, Lappeenranta Degree Programme in Mechanical Engineering and Production Technology Thesis 2017

[9] Katrine Sivertsen, polymer foams , 3.063 Polymer Physics, Spring 2007

[10] https://libraries.io/github/winder/Universal-G-Code-Sender

[11]R. K. Roy ,"Aprimer on the Taguchi method",1ST Edition (New york: Van Nostrand Reinhold ,1990)

[12] BalaRaju.J, Anup Kumar.J, Dayal Saran.P, Dr.C.S.Krishna Prasad Rao"Application of Taguchi Technique for Identifying Optimum Surface Roughness in CNC end Milling Process", International Journal of Engineering Trends and Technology (IJETT), V21(2),103-110 March 2015.

[13] M.Vishnu Vardhan, G.Sankaraiah , M.Yohan , H.Jeevan Rao , ”Optimization of Parameters in CNC milling of P20 steel using Response Surface methodology and Taguchi Method” ,Science Direct,Volume 4, Issue 8, , Pages 9163-9169,2017.

[14] Hanan H. Murad , “Parametric Investigation of the Magnetic Abrasive Finishing Method” , Al-Khwarizmi College of Engineering of University of Baghdad, 2017

[15] Shouvik Ghosh, Prasanta Sahoo, and Goutam Sutradhar, “ Tribological Performance Optimization of Al-7.5\% SiCp Composites Using the Taguchi Method and Grey Relational Analysis”, Journal of Composites, Volume, Article ID 274527, 9 pages, 2013

[16] Marwa K. Qate'a , Ali H . kadhum , Faiz F. Mustafa, “The Influence of the Magnetic Abrasive Finishing System for Cylindrical Surfaces on the Surface Roughness and MRR “, Al-Khwarizmi Engineering Journal ,Vol 11 No 3 (2015): 2015 


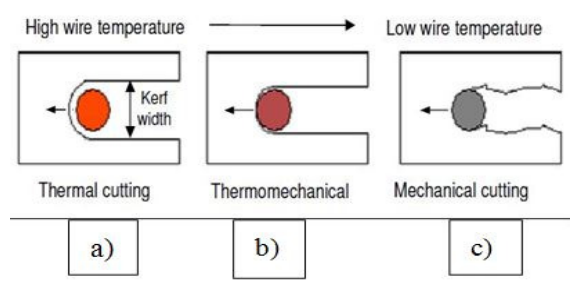

Fig 1.Cutting mechanism [1]

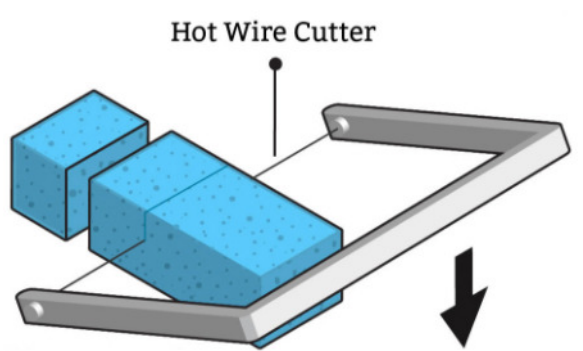

Fig2. The hot-wire foam cutter[ 2]

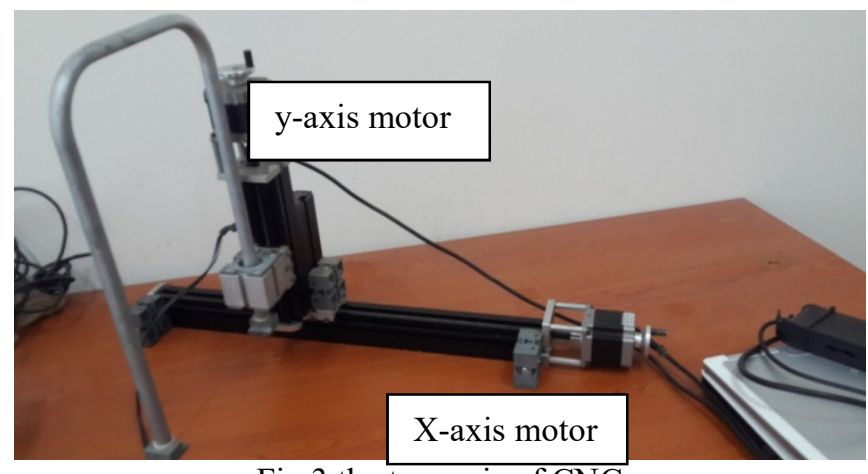

Fig 3 the two axis of $\mathrm{CNC}$

Table 1 specifications of CNC machine

\begin{tabular}{|l|l|}
\hline No. of CNC axes & 2 axis \\
\hline motors & Stepper $1.8^{\circ}, 2 \mathrm{~A}, 12 \mathrm{~V}$ \\
\hline Cutting bow & Width $170 \mathrm{~mm}$, height $350 \mathrm{~mm}$ \\
\hline
\end{tabular}

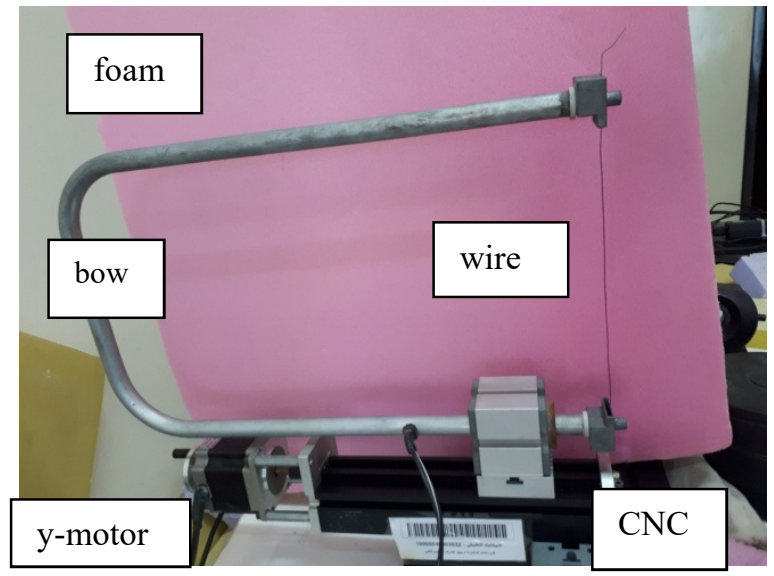

fig 4 . The aluminium elbow with the ceramic cylinders 


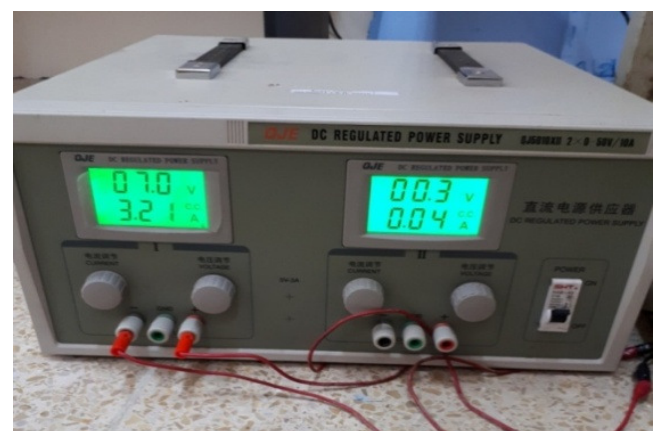

Fig 5 DC regulated power supply

Table.2. the relation between temperature and voltage

\begin{tabular}{|l|l|l|l|l|l|l|}
\hline \multicolumn{5}{|c|}{ Voltage (volt) } & Temp. ${ }^{\circ} \mathrm{C}$ \\
\cline { 1 - 6 } No. & $\mathrm{d}(0.3 \mathrm{~mm})$ & $\mathrm{d}(0.4 \mathrm{~mm})$ & $\begin{array}{l}\mathrm{d} \\
(0.5 \mathrm{~mm})\end{array}$ & $\mathrm{d}(0.7 \mathrm{~mm})$ & $\begin{array}{l}\mathrm{d} \\
(0.8 \mathrm{~mm})\end{array}$ \\
\hline 1 & 9.3 & 6.6 & 5.5 & 4.8 & 4.4 & 100 \\
\hline 2 & 10.2 & 7.5 & 6.0 & 5.2 & 4.8 & 120 \\
\hline 3 & 10.6 & 8.4 & 6.5 & 5.4 & 5.0 & 130 \\
\hline 4 & 11.8 & 8.8 & 7.0 & 5.8 & 5.3 & 150 \\
\hline 5 & 12.5 & 9.7 & 7.5 & 6.2 & 5.6 & 160 \\
\hline
\end{tabular}

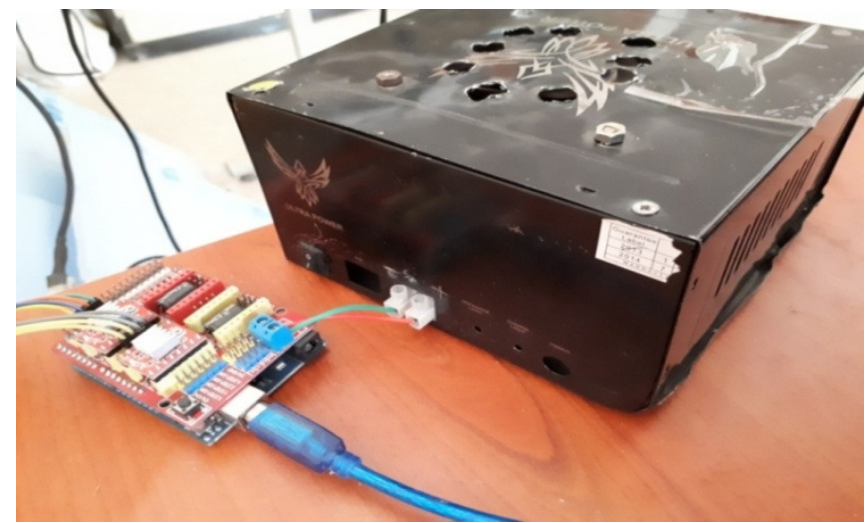

Fig 6. DC regulated power supply (smps)

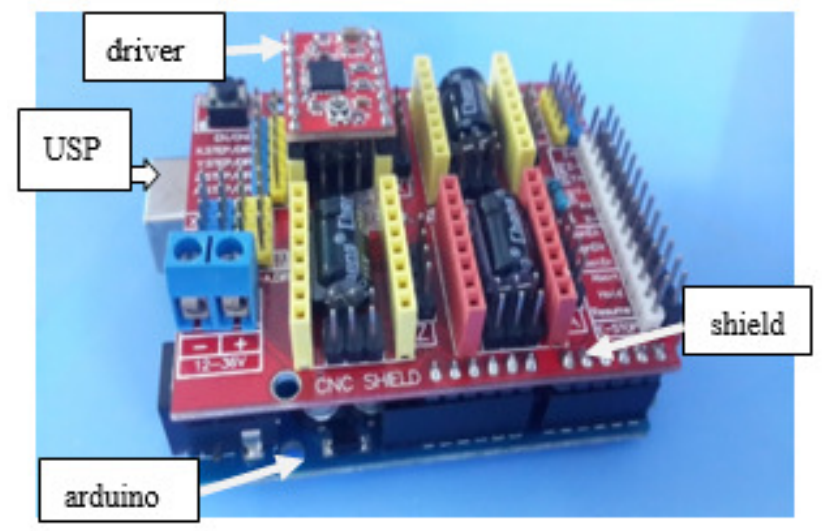

Fig 7. assembled CNC shield 


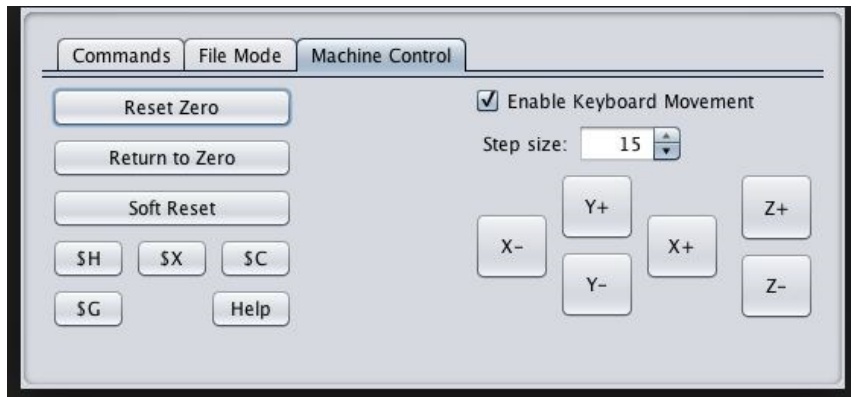

Fig 8. screenshot of the Gcode universal

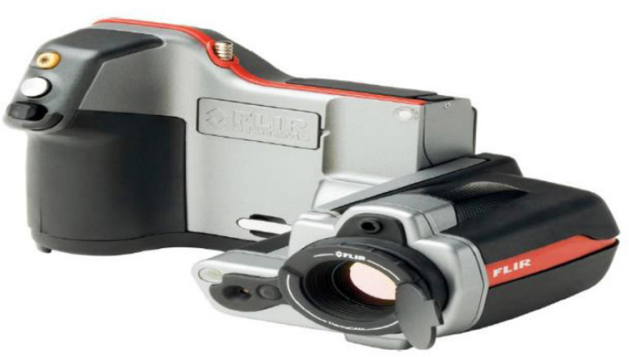

Fig 9. infrared thermo camera FLIR T335

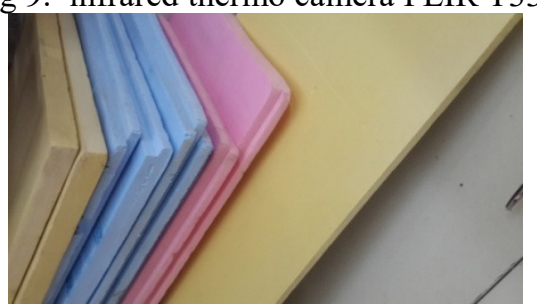

Fig 10 foam colors

Table 3. density of foam

\begin{tabular}{|l|l|}
\hline Foam color & Densities $\left(\mathrm{g} / \mathrm{cm}^{3}\right)$ \\
\hline purple & 0.037 \\
\hline yellow & 0.032 \\
\hline Blue & 0.029 \\
\hline Pink & 0.027 \\
\hline white & 0.01 \\
\hline
\end{tabular}

Table 5 The parameters and their levels

\begin{tabular}{|l|l|l|l|l|l|l|l|l|}
\hline NO. & PARAMETER & \multirow{2}{*}{ UNIT } & \multirow{2}{*}{ CODE } & \multicolumn{5}{|c|}{ LEVEL } \\
\cline { 5 - 9 } & & & 1 & 2 & 3 & 4 & 5 \\
\hline 1 & Wire Temperature & ${ }^{\circ} \mathrm{C}$ celisus & $\mathrm{A}$ & 100 & 120 & 130 & 150 & 160 \\
\hline 2 & Wire diameter & $\mathrm{mm}$ & $\mathrm{B}$ & 0.3 & 0.4 & 0.5 & 0.7 & 0.8 \\
\hline 3 & Cutting Velocity & $\mathrm{mm} / \mathrm{min}$ & $\mathrm{C}$ & 200 & 300 & 400 & 500 & 600 \\
\hline & Foam density & $\mathrm{gm} / \mathrm{cm}^{3}$ & $\mathrm{D}$ & 0.01 & 0.027 & 0.029 & 0.032 & 0.037 \\
\hline
\end{tabular}


Table6. Orthogonal Array

\begin{tabular}{|l|l|l|l|l|}
\hline no. & A code & B code & C code & D code \\
\hline 1 & 1 & 1 & 1 & 1 \\
\hline 2 & 1 & 2 & 2 & 2 \\
\hline 3 & 1 & 3 & 3 & 3 \\
\hline 4 & 1 & 4 & 4 & 4 \\
\hline 5 & 1 & 5 & 5 & 5 \\
\hline 6 & 2 & 1 & 2 & 3 \\
\hline 7 & 2 & 2 & 3 & 4 \\
\hline 8 & 2 & 3 & 4 & 5 \\
\hline 9 & 2 & 4 & 5 & 1 \\
\hline 10 & 2 & 5 & 1 & 2 \\
\hline 11 & 3 & 1 & 3 & 5 \\
\hline 12 & 3 & 2 & 4 & 1 \\
\hline 13 & 3 & 3 & 5 & 2 \\
\hline 14 & 3 & 4 & 1 & 3 \\
\hline 15 & 3 & 5 & 2 & 4 \\
\hline 16 & 4 & 1 & 4 & 2 \\
\hline 17 & 4 & 2 & 5 & 3 \\
\hline 18 & 4 & 3 & 1 & 4 \\
\hline 19 & 4 & 4 & 2 & 5 \\
\hline 20 & 4 & 5 & 3 & 1 \\
\hline 21 & 5 & 1 & 5 & 4 \\
\hline 22 & 5 & 2 & 1 & 5 \\
\hline 23 & 5 & 3 & 2 & 1 \\
\hline 24 & 5 & 4 & 3 & 2 \\
\hline 25 & 5 & 5 & 4 & 3 \\
\hline & & & & \\
\hline
\end{tabular}




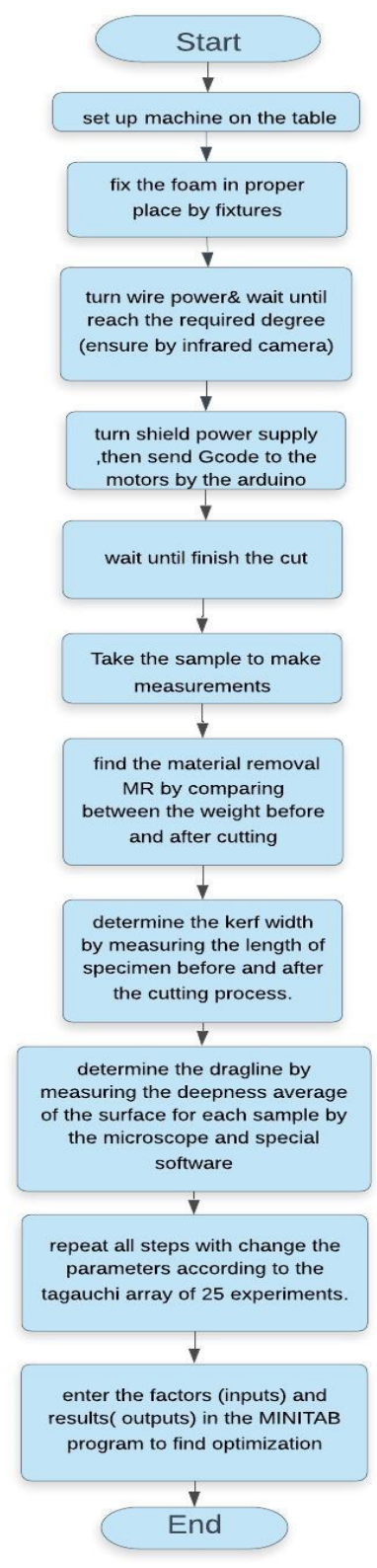

Fig 11. Procedure of foam cutting operation

Table 7.The main effect of the $\mathrm{S} / \mathrm{N}$ ratio for $\mathrm{MR}$

\begin{tabular}{|c|c|c|c|c|c|}
\hline \multicolumn{7}{|c|}{ s/n ratio } & for response \\
\hline level & $\mathrm{A}$ & $\mathrm{B}$ & $\mathrm{C}$ & $\mathrm{D}$ & level \\
\hline 1 & 59.21 & 48.98 & 46.19 & 44.26 & 1 \\
\hline 2 & 41.81 & 45.20 & 46.35 & 44.26 & 2 \\
\hline 3 & 43.37 & 51.21 & 45.38 & 38.99 & 3 \\
\hline 4 & 45.29 & 37.76 & 44.05 & 45.25 & 4 \\
\hline 5 & 45.99 & 45.84 & 45.63 & 39.96 & 5 \\
\hline Delta & 17.39 & 13.46 & 2.30 & 17.17 & Delta \\
\hline Rank & 1 & 3 & 4 & 2 & Rank \\
\hline \multicolumn{7}{|c|}{ S/N ratio optimization } \\
\end{tabular}


Table 8 . The main effect of the mean for MR

\begin{tabular}{|l|l|l|l|l|}
\hline \multicolumn{4}{|l}{ Means } & for response \\
\hline level & A & B & C & D \\
\hline 1 & 0.001700 & 0.005620 & 0.007940 & 0.002860 \\
\hline 2 & 0.008225 & 0.006120 & 0.007020 & 0.007160 \\
\hline 3 & 0.008020 & 0.003767 & 0.007750 & 0.011575 \\
\hline 4 & 0.007120 & 0.013275 & 0.007133 & 0.005975 \\
\hline 5 & 0.007800 & 0.006975 & 0.005950 & 0.010233 \\
\hline Delta & 0.006525 & 0.009508 & 0.001990 & 0.008715 \\
\hline Rank & 3 & 1 & 4 & 2 \\
\hline \multicolumn{5}{|r}{ Mean optimization } \\
\hline
\end{tabular}

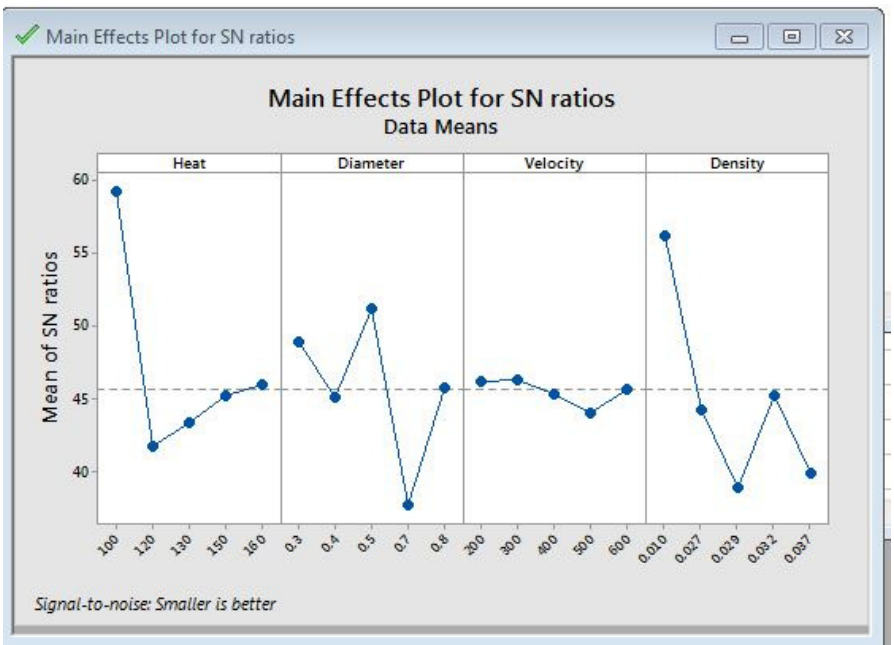

Fig 12. main effects plot $\mathrm{S} / \mathrm{N}$ ratio plot for $\mathrm{MR}$

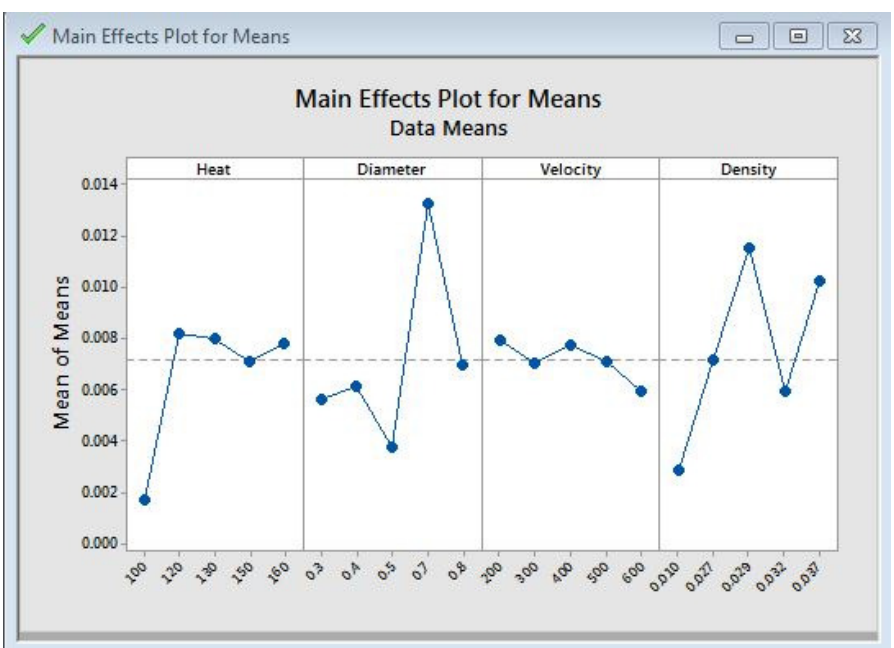

Fig 13. main effects plot of means for MR

Table 9. The prediction of the mean and $\mathrm{S} / \mathrm{N}$ ratio of $\mathrm{MR}$

\begin{tabular}{|l|l|l|l|l|l|l|l|}
\hline \multicolumn{4}{|l|}{ S/N ratio } & \multicolumn{3}{l|}{ mean } \\
\hline A & B & C & D & A & B & C & D \\
\hline 1 & 3 & 2 & 4 & 2 & 4 & 1 & 3 \\
\hline \multicolumn{2}{|l|}{ S/N Ratio } & \multicolumn{2}{|l|}{ Mean } & \multicolumn{2}{l}{ S/N ratio } & mean \\
\hline 63.3489 & -0.00066 & 38.4977 & 0.01147 \\
\hline
\end{tabular}


Table 10. The main effect of the $\mathrm{S} / \mathrm{N}$ ratio for kerfwidth $\mathrm{s} / \mathrm{n}$ ratio for response

\begin{tabular}{|l|l|l|l|l|l|}
\hline level & A & B & C & D & \\
\hline 1 & 20.00 & 18.09 & 16.39 & 15.18 & \\
\hline 2 & 24.12 & 26.41 & 17.39 & 18.80 & \\
\hline 3 & 19.30 & 15.99 & 21.99 & 17.61 & \\
\hline 4 & 15.18 & 16.99 & 17.99 & 24.12 & \\
\hline 5 & 16.39 & 13.10 & 20.00 & 17.99 & \\
\hline Delta & 8.94 & 13.31 & 5.60 & 8.94 & \\
\hline Rank & 2 & 1 & 4 & 3 & \\
\hline
\end{tabular}

$\mathrm{S} / \mathrm{N}$ ratio optimization Table 11 .

\begin{tabular}{|l|l|l|l|l|}
\hline & Means & \multicolumn{4}{l|}{ for response } \\
\hline level & A & B & C & D \\
\hline 1 & 0.12500 & 0.13000 & 0.16000 & 0.20000 \\
\hline 2 & 0.11375 & 0.07100 & 0.15000 & 0.13000 \\
\hline 3 & 0.11000 & 0.16667 & 0.17625 & 0.13750 \\
\hline 4 & 0.20000 & 0.15000 & 0.13333 & 0.11375 \\
\hline 5 & 0.16000 & 0.23750 & 0.10000 & 0.13333 \\
\hline Delta & 0.09000 & 0.16650 & 0.07625 & 0.08625 \\
\hline Rank & 2 & 1 & 4 & 3 \\
\hline
\end{tabular}

Mean optimization

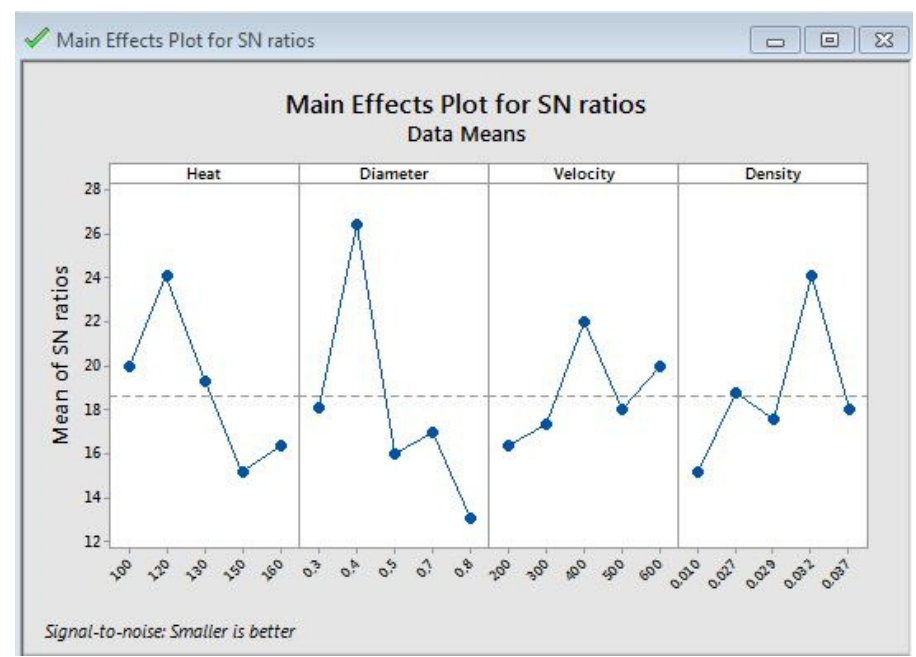

Fig 14. main effects plot of $\mathrm{S} / \mathrm{N}$ ratio for kerfwidth

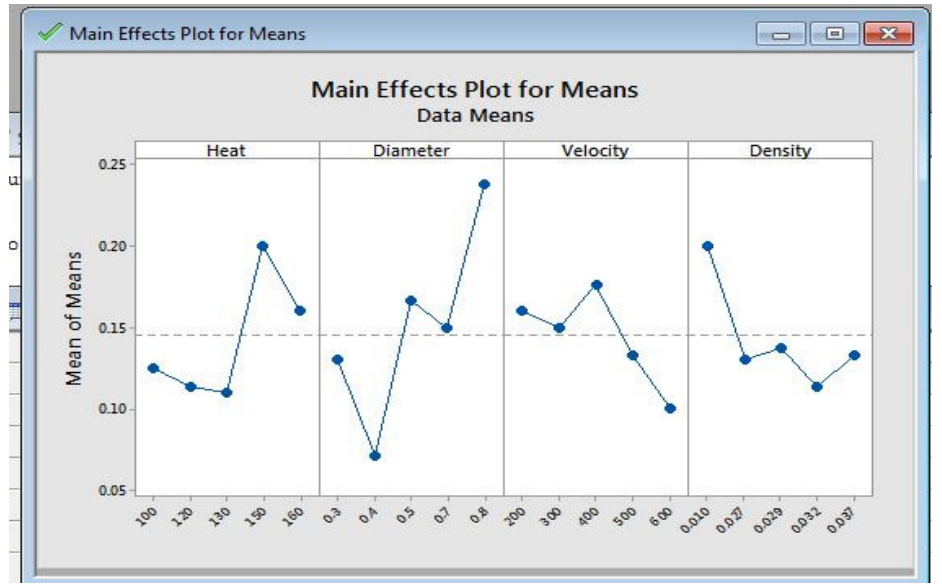

Fig 15. main effects plot of means for kerfwidth 
Table 12 The prediction of the mean and $\mathrm{S} / \mathrm{N}$ ratio of kerfwidth

\begin{tabular}{|c|c|c|c|c|c|c|c|}
\hline \multicolumn{4}{|c|}{ S/N ratio } & \multicolumn{5}{|c|}{ mean } \\
\hline A & B & C & D & A & B & C & D \\
\hline 2 & 2 & 3 & 4 & 4 & 5 & 3 & 1 \\
\hline \multicolumn{2}{|c|}{ S/N ratio } & \multicolumn{2}{|c|}{ Mean } & \multicolumn{2}{|c|}{ S/N ratio } & \multicolumn{2}{|c|}{ mean } \\
\hline \multicolumn{2}{|c|}{32.7496} & \multicolumn{2}{|c|}{0.083} & \multicolumn{2}{|c}{10.9691} & 0.315 \\
\hline
\end{tabular}

Table 13

\begin{tabular}{|l|l|l|l|l|}
\hline level & A & B & C & D \\
\hline 1 & 26.33 & 29.25 & 32.08 & 35.46 \\
\hline 2 & 31.46 & 27.74 & 27.89 & 24.44 \\
\hline 3 & 28.97 & 26.21 & 27.83 & 31.30 \\
\hline 4 & 26.74 & 31.64 & 30.55 & 21.70 \\
\hline 5 & 5.12 & 5.42 & 6.02 & 13.75 \\
\hline Delta & 4.74 & 9.71 & 3.91 & 30.77 \\
\hline Rank & 4 & 3 & 2 & 1 \\
\hline \multicolumn{5}{|c|}{ S/N ratio optimization } \\
\hline \multicolumn{7}{|c|}{} \\
\hline
\end{tabular}

Table 14

\begin{tabular}{|l|l|l|l|l|}
\hline Means & \multicolumn{4}{l|}{ for response } \\
\hline level & A & B & C & D \\
\hline 1 & 26.50 & 36.00 & 43.40 & 62.20 \\
\hline 2 & 51.00 & 38.40 & 33.00 & 19.80 \\
\hline 3 & 39.00 & 26.00 & 29.75 & 41.50 \\
\hline 4 & 23.80 & 44.25 & 44.33 & 12.75 \\
\hline 5 & 37.20 & 32.50 & 30.75 & 43.33 \\
\hline Delta & 27.20 & 18.25 & 14.58 & 49.45 \\
\hline Rank & 2 & 3 & 4 & 1 \\
\hline
\end{tabular}

Mean optimization

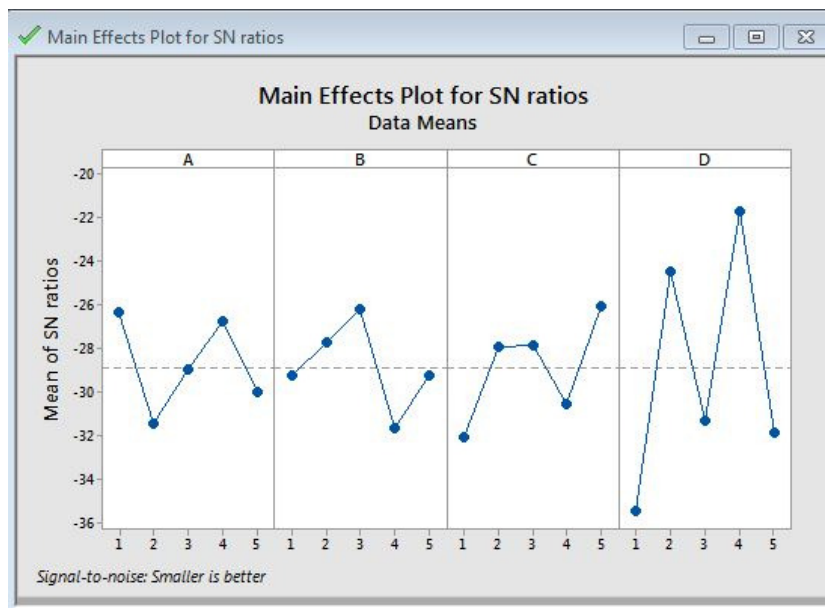

Fig 16. main effects plot of $\mathrm{S} / \mathrm{N}$ ratio for dragline 


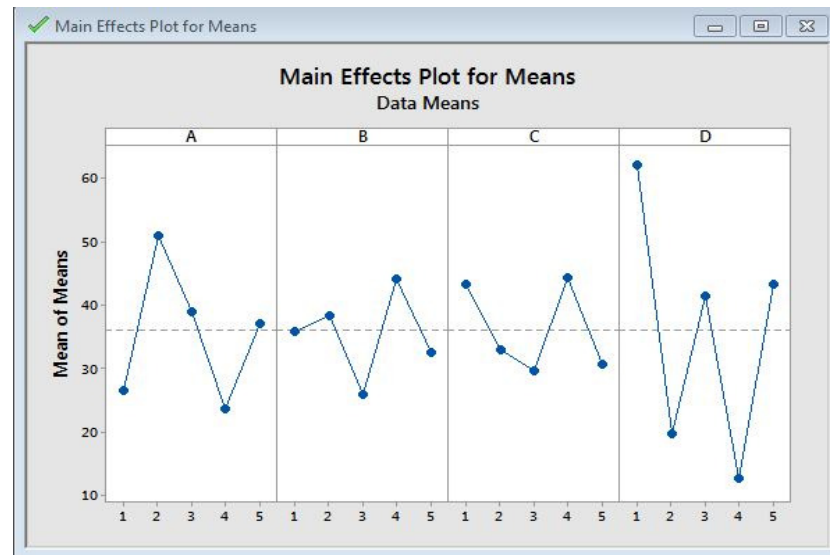

Fig 17. effects plot of means for dragline

Table15. The prediction of the mean and $\mathrm{S} / \mathrm{N}$ ratio of dragline

\begin{tabular}{|l|l|l|l|l|l|l|l|}
\hline \multicolumn{4}{|l|}{ S/N ratio } & \multicolumn{3}{l|}{ mean } \\
\hline $\mathrm{A}$ & $\mathrm{B}$ & $\mathrm{C}$ & $\mathrm{D}$ & $\mathrm{A}$ & $\mathrm{B}$ & $\mathrm{C}$ & $\mathrm{D}$ \\
\hline 2 & 4 & 1 & 1 & 2 & 4 & 4 & 1 \\
\hline S/N ratio & \multicolumn{2}{|l|}{ Mean } & \multicolumn{2}{|l|}{ S/N ratio } & \multicolumn{2}{|l|}{ mean } \\
\hline 44.2893 & 96.6 & \multicolumn{3}{|l|}{38.5394} & \multicolumn{3}{|l|}{83.7} \\
\hline
\end{tabular}

Table 16. ANOVA for MR

\begin{tabular}{|c|c|c|c|c|c|}
\hline Source & DF & Adj SS & F-Value & P-Value & Contributed (\%) \\
\hline Temp. A & 4 & 0.000033 & 0.65 & 0.655 & 3.4 \\
\hline Diameter B & 4 & 0.000160 & 8.58 & 0.030 & 46.8 \\
\hline Velocity C & 4 & 0.000039 & 1.04 & 0.484 & 5.5 \\
\hline Density D & 4 & 0.000136 & 7.04 & 0.043 & 38.6 \\
\hline Error & 4 & 0.000038 & & & 5.5 \\
\hline Total & 20 & 0.000406 & & & 100 \\
\hline
\end{tabular}

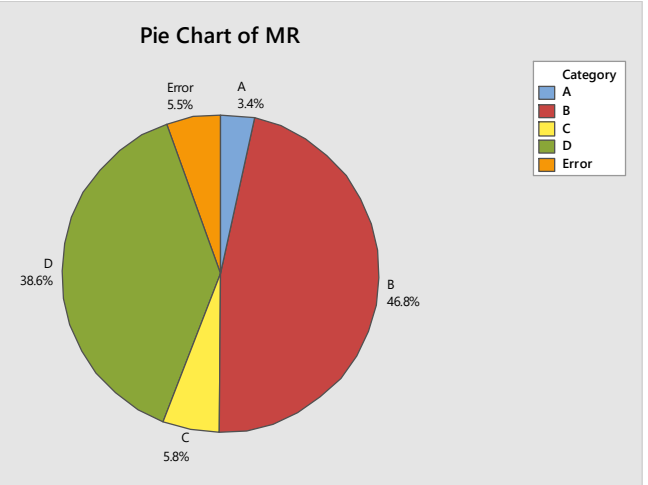

Fig 18 The contributed percentage of the factor for MR

Table 17.ANOVA for kerf width

\begin{tabular}{|c|r|c|c|c|c|}
\hline Source & DF & Adj SS & F-Value & P-Value & Contributed(\%) \\
\hline Temp. A & 4 & 0.03306 & 2.60 & 0.189 & 24.6 \\
\hline Diameter B & 4 & 0.04002 & 3.70 & 0.116 & 35.0 \\
\hline Velocity C & 4 & 0.01414 & 1.12 & 0.456 & 10.6 \\
\hline Density D & 4 & 0.03318 & 2.15 & 0.239 & 20.4 \\
\hline Error & 4 & 0.01270 & & & 9.4 \\
\hline Total & 20 & 0.13310 & & & 100 \\
\hline
\end{tabular}




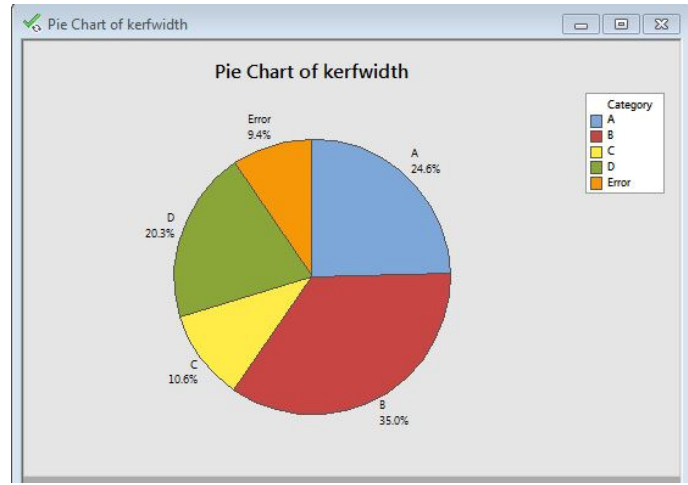

Fig 19 The contributed percentage of the factor for kerf width

Table 18. ANOVA for dragline

\begin{tabular}{|c|r|c|c|c|c|}
\hline Source & DF & Adj SS & F-Value & P-Value & Contributed(\%) \\
\hline Temp. A & 4 & 3084.8 & 2.09 & 0.247 & 15.0 \\
\hline Diameter B & 4 & 510.5 & 0.35 & 0.836 & 4.00 \\
\hline Velocity C & 4 & 1229.5 & 0.83 & 0.568 & 11.6 \\
\hline Density D & 4 & 7215.6 & 4.88 & 0.077 & 57.6 \\
\hline Error & 4 & 1477.2 & & & 11.8 \\
\hline Total & 20 & 26812.4 & & & 100 \\
\hline
\end{tabular}

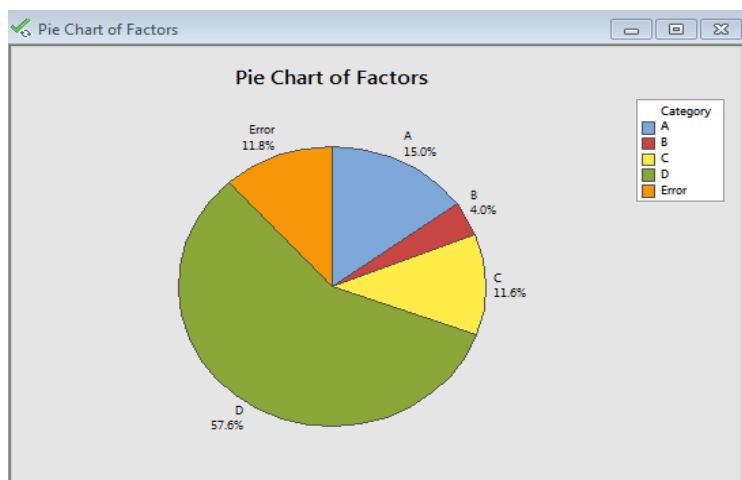

Fig 20 The contributed percentage of the factor for dragline 